\title{
The exterior cusp and its boundary with the magnetosheath: Cluster multi-event analysis
}

\author{
B. Lavraud ${ }^{1 *}$, T. D. Phan ${ }^{2}$, M. W. Dunlop ${ }^{3}$, M. G. G. T. Taylor ${ }^{4}$, P. J. Cargill ${ }^{5}$, J.-M. Bosqued ${ }^{1}$, I. Dandouras ${ }^{1}$, \\ H. Rème ${ }^{1}$, J.-A. Sauvaud ${ }^{1}$, C. P. Escoubet ${ }^{6}$, A. Balogh ${ }^{5}$, and A. Fazakerley ${ }^{7}$ \\ ${ }^{1}$ Centre d'Etude Spatiale des Rayonnements, Toulouse, France \\ ${ }^{2}$ Space Science Laboratory, University of California, Berkeley, USA \\ ${ }^{3}$ Rutherford Appleton Laboratory, Didcot, UK \\ ${ }^{4}$ Space and Atmospheric Sciences, Los Alamos National Laboratory, NM, USA \\ ${ }^{5}$ Imperial College, London, UK \\ ${ }^{6}$ ESA/ESTEC, Noordwiijk, The Netherlands \\ ${ }^{7}$ Mullard Space Science Laboratory, Dorking, Surrey, UK \\ *now at: Space and Atmospheric Sciences, Los Alamos National Laboratory, NM, USA
}

Received: 26 February 2004 - Revised: 26 May 2004 - Accepted: 2 June 2004 - Published: 7 September 2004

\begin{abstract}
We report on the observation of three high-altitude cusp crossings by the Cluster spacecraft under steady northward IMF conditions. The focus of this study is on the exterior cusp and its boundaries. At the poleward edge of the cusp, large downward jets are present; they are characterized by a dawn-dusk component of the convection velocity opposite to the IMF $B_{y}$ direction and a gradual evolution (velocity filter effect) corresponding to an injection site located at the high-latitude magnetopause tailward of the cusp, with subsequent sunward convection. As one moves from the poleward edge into the exterior cusp proper, the plasma gradually becomes stagnant as the result of the mirroring and scattering of the aforementioned plasma flows. The existence of such a stagnant region (Stagnant Exterior Cusp: SEC) is found in all events studied here even when the IMF $B_{y}$ is large and the clock angle is $\sim 90^{\circ}$. The SEC-magnetosheath boundary appears as a spatial structure that has a normal component of the magnetic field pointing inward, in accordance with a probable connection between the region and the magnetosheath (with northward field). This boundary generally has a deHoffmann-Teller velocity that is slow and oriented sunward and downward, compatible with a discontinuity propagating from a location near the high-latitude magnetopause. Although the tangential stress balance is not always satisfied, the SEC-magnetosheath boundary is possibly a rotational discontinuity. Just outside this boundary, there exists a clear sub-Alfvénic plasma depletion layer (PDL). These results are all consistent with the existence of a nearly steady reconnection site at the high-latitude magnetopause tailward of the cusp. We suggest that the stability of the external discontinuity (and of the whole region) is maintained by the presence of the sub-Alfvénic PDL. However, examination
\end{abstract}

Correspondence to: B. Lavraud

(lavraud@lanl.gov) of the electron data shows the presence of heated electrons propagating parallel to the magnetic field (upward) just outside of the SEC-magnetosheath boundary. This appears inconsistent with their source being the northern lobe reconnection site. Finally, the definition of the magnetopause at high latitudes is revisited. To define the SEC-magnetosheath boundary as the magnetopause would lead to the misnaming of the "exterior cusp".

Key words. Magnetospheric physics (Magnetopause, cusp, and boundary layers; Solar wind-magnetosphere interactions; Magnetospheric configuration and dynamics)

\section{Introduction}

The high-altitude cusp regions of the magnetosphere contain information on plasma entry that occurs at the local boundaries as well as from remote entry sites. On the basis of HEOS-2 data, Paschmann et al. (1976) and Haerendel et al. (1978) proposed a global picture of the distant cusp region as comprising an "entry layer" at its equatorward edge, and a central "stagnation region", characterized by low and variable plasma flows and magnetic fields. The "plasma mantle" region was defined as the boundary layer located at the poleward edge of the cusp, where the observed up and tailward flowing plasma is that of the cusp which mirrored at low altitudes (Rosenbauer et al., 1975). This plasma gains access to the tail of the magnetosphere.

Haerendel et al. (1978) further focused on the probable occurrence of diffusion at the different boundaries surrounding the stagnation region while Haerendel (1978) investigated the possible formation of eddies in the flows and fields. The boundary delimiting the stagnation region from the free-flow magnetosheath was studied by Scarf et al. (1974) and Hansen 


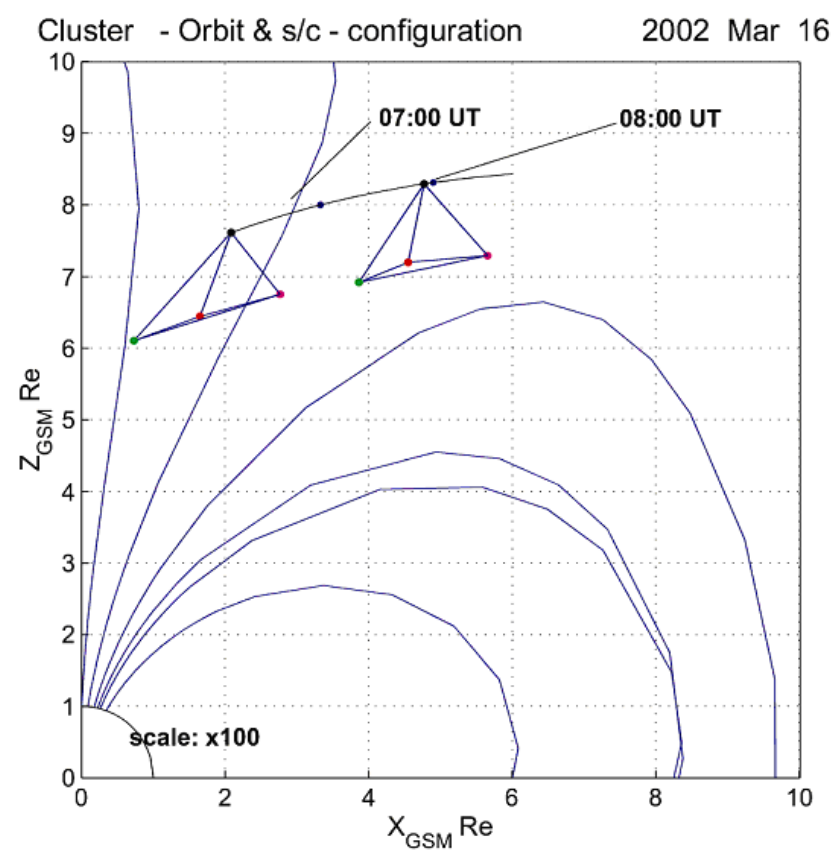

Fig. 1. Orbit of the Cluster fleet for the 16/03/2002 event, as described in Sect. 2.1.

et al. (1976). They investigated a possible shock interpretation, as first proposed by Walters (1966), (see also Cargill, 1999), but could not establish its actual nature.

More recently, the possible importance of the reconnection process (Dungey, 1961) in structuring the cusp has been widely investigated (Vasyliunas, 1995; Fuselier et al., 2000a; Russell et al., 2000; Fedorov et al., 2000; Onsager et al., 2001; Lavraud et al., 2002). Under southward IMF, subsolar reconnection is expected to take place and large-scale tailward convection is thought to occur in the exterior cusp region (Vasyliunas, 1995). Such characteristics have been confirmed by observation, most recently in a Cluster case study by Cargill et al. (2004). Under steady northward IMF, due to reconnection occurring poleward of the cusp (Gosling et al., 1991; Kessel et al., 1996), a different global cusp structure may be expected. It is characterized by reversed dispersion, following from a reversed, sunward convection in the region. However, the evidence for such a coherent, reversed cusp structure at high-altitudes (and, for instance, the plasma flow evolution) has been revisited by Fuselier et al. (2000a), who argued for the possible simultaneous occurrence of lobe and sub-solar reconnection even under northward IMF conditions, on the basis of the component merging process. Contradictory conclusions, favoring the antiparallel merging process, have, however, been given for the same event by Russell et al. (2000).

Under northward IMF, a large area of stagnant plasma in the exterior cusp has recently been reported (Lavraud et al., 2002). It was further revealed that lobe reconnection would qualitatively allow this region to exist, but the stability of the whole region would eventually require the stability of the reconnection site in the lobes. In line with this, Fuselier et al. (2000b) suggested that the formation of a plasma depletion layer (PDL) (Zwan and Wolf, 1976) may allow for the presence of sub-Alfvénic flows at the high-latitude magnetopause, which, in turns, would prevent the lobe reconnection site to be swept tailward. The presence of such a PDL at high latitudes was recently shown by Avanov et al. (2001) and Phan et al. (2003). However, the stability, origin and nature of the exterior cusp-magnetosheath boundary (Walters, 1966; Scarf et al., 1974; Hansen et al., 1976; Yamauchi and Lundin, 1997; Savin et al., 1998; Lavraud et al., 2002) are still unclear.

The present paper follows on from a case study of the exterior cusp and its surrounding boundaries under northward IMF (Lavraud et al., 2002) (referenced herein as paper 1). In paper 1, the descriptive term Stagnant Exterior Cusp (SEC) was introduced, which is simply used as a framework. It was shown to be located at large distances $\left(>9 R_{E}\right)$, and characterized by isotropic ion distribution functions and very low magnetic field magnitudes ( $\leq 30 \mathrm{nT})$.

The present study introduces three more Cluster events and reinforces some of the conclusions reached in the case study of paper 1. At the same time this work sheds new light on the structure of the exterior cusp and its boundaries under northward IMF, and especially that of the SECmagnetosheath boundary. In Sect. 2 we present the Cluster instrumentation and orbit. Section 3 is dedicated to the presentation of three encounters which occurred during spring 2002. We revisit the data in Sect. 4, where we discuss the plasma evolution throughout the high-altitude cusp and towards the SEC, and then deal with the structure of the region, and that of the SEC-magnetosheath boundary. Section 5 summarizes our findings.

\section{Orbits and instrumentation}

\subsection{Orbits presentation}

The Cluster mission is ideal for high-altitude cusp investigations both in terms of orbit and plasma and field measurements. Cluster consists of a fleet of four identical spacecraft that maintain a closely separated spatial array $(\sim 100 \mathrm{~km}$ for the three present events), which evolves substantially in shape around the orbit.

On 16 March 2002, the Cluster array flew outbound through the northern lobe, cusp and magnetosheath between 05:30 UT and 09:00 UT. Figure 1 shows the projection of the Cluster orbit (lying within 11:30 and 12:00 MLT) projected in the $\mathrm{X}, \mathrm{Z}_{G S M}$ plane (hour intervals marked as blue dots). Superimposed with spacecraft 1 (black) orbit track are the shapes of the tetrahedra (scale factor of 100) at two arbitrary different times. The other spacecraft are color coded as: 2 (red), 3 (green) and 4 (magenta). The background magnetic field lines (blue) have been computed using the Tsyganenko (T89) magnetic field model (Tsyganenko, 1989). The three events analyzed here are from 16, 21, and 23 March 
$2002(16 / 03 / 2002,21 / 03 / 2002$ and 23/02/2002). The orbits of the two other events studied here (21/03/2002 and 23/03/2002) are not shown; they occurred within a week after the 16/03/2002 event and are similar.

\subsection{Instrumentation}

We use ion measurements from the Cluster Ion Spectrometry (CIS) experiment (Rème et al., 2001). The CIS package obtains full three-dimensional ion distribution functions with high time resolution (down to 1 spin resolution $\sim 4 \mathrm{~s}$ ). CIS is composed of two complementary sensors, the CODIF sensor (COmposition and DIstribution Function analyser) which uses time-of-flight measurements in order to resolve ion masses. The second detector is the Hot Ion Analyser (HIA). It does not separate ion species but has a better angular resolution. The magnetic field vectors were sampled by the fluxgate magnetometer experiment (FGM) (Balogh et al., 2001). Spin-averaged data, as well as higher resolution $(3 \mathrm{~Hz})$ data, are used in this study. The electron data come from the Plasma Electron And Current Experiment (PEACE). It consists of two sensors, HEEA (High Energy Electron Analyser) and LEEA (Low Energy Electron Analyser), mounted on diametrically opposite sides of the spacecraft. They are designed to measure the three-dimensional velocity distributions of electrons in the range $0.6 \mathrm{eV}$ to $\sim 26 \mathrm{keV}$. In this study we show spectrograms of four second resolution data. For further instrument information, the reader is referred to Johnstone et al. (1997) and Szita et al. (2001).

\section{Observations and analysis}

This study focuses on the analysis of three recent Cluster exterior cusp passes: 16/03/2002, 21/03/2002 and 23/03/2002. They have been chosen for two reasons: (1) they show clear crossing of the low magnetic field exterior cusp region and its direct boundary with the magnetosheath and (2) they occurred under persistent northward IMF conditions. Similarities and differences with the event depicted in paper 1 $(04 / 02 / 2001)$ will be noted throughout the paper. We analyze the overall cusp structure and then focus on the exterior cusp-magnetosheath boundary.

\subsection{The $16 / 03 / 2002$ event}

Figures 2 shows combined CIS, FGM and time-shifted ACE IMF data (all in GSM coordinates). Below the panel composer, the position of spacecraft 1 in GSM coordinates is displayed for five different times. On the left-hand side of the panel composer, 2-D cuts of the ion distribution functions (in the $\left(V_{/ /}, V_{\perp}\right)$ plane) are also shown for the five times of interest, indicated by dashed vertical lines in the main panel composer.

In Fig. 2, the Cluster fleet was at first in the tenuous (panel (b)) northern lobe region. At 06:00 UT, they entered the lobecusp boundary which was characterized by high-speed downward flows $\left(V_{z}<0\right)$. From then on an energy-time disper- sion was observed; this is apparent in the low-energy cutoff of the spectrogram that gradually decreased between 06:00 and 06:30 UT (panel (a)). Within this large-scale structure, a few smaller-scale injections also occurred, for example, at 06:18 and 06:30 UT. On average, a gradual decrease was observed in the plasma velocity and temperature (panels (c) and (e)) as the spacecraft went deeper into the exterior cusp. As seen in the evolution of the bulk velocity (panel (c)), the precipitating plasma bounced in the cusp throat, and a counter-streaming population was progressively detected (distribution function I). The spacecraft entered the stagnant exterior cusp (SEC) (as defined in paper 1) from around 07:10 UT when the magnetic field became highly depressed and the velocities were low (panels (c), (d) and (f)). It showed highly isotropic ion distribution functions (number II) that contrast with the counter-streaming nature of distribution I. The plasma bulk velocity had a dominant downward component within the plasma flows at the beginning of the cusp interval (panel (c)). The dominant dawnward direction of the convection (panel (d)) measured in these flows evolved into a clearly sunward and downward orientation in the more distant cusp and SEC, where it became particularly low.

The spacecraft finally encountered the boundary separating the SEC from the magnetosheath around 08:11 UT, where the plasma and field parameters exhibit large changes. From the magnetosheath to the SEC, this discontinuity shows a large decrease in plasma flow and magnetic field strength and an abrupt increase in temperature (with a factor of $\sim 3$ for the perpendicular temperature $\left(T_{\perp}\right)$ and $\sim 6$ for the parallel temperature $\left(T_{/ /}\right)$). Two distribution functions sampled inside the boundary are displayed as number III and IV in Fig. 2. These look bi-directional and therefore differ from the ones in the adjacent SEC (II) and magnetosheath (V). Within the boundary, the entering, field-aligned population appears colder than the outgoing, anti-field-aligned population (distributions III and IV). This behavior is comparable to observations of a similar boundary in paper 1 .

Figures $5 \mathrm{a}, \mathrm{b}$ and $\mathrm{c}$ presents the hodograms of the SECmagnetosheath boundaries for the three events selected in this paper. The hodograms are displayed in the LMN coordinates directly arising from the eigenvectors of the Minimum Variance Analysis (MVA) (Sonnerup and Cahill, 1967) of the magnetic field on board spacecraft 1 (from FGM $3 \mathrm{~Hz}$ data). In the three events analyzed here, the magnetic field intervals used for the MVA are systematically centered on the temperature jump that always accompanies the magnetic signature characteristic of the discontinuity. Table 1 summarizes the results of the technique for all four spacecraft (and for the three events analyzed in this paper).

The hodogram of the SEC-magnetosheath boundary on 16/03/2002 is shown in Fig. 5a, and shows a small inward normal magnetic field component $(\sim-1.2 \mathrm{nT})$, on average, as well as a possible " $\mathrm{S}$ " shape in the $\left(B_{l}, B_{m}\right)$ plane. Application of the MVA technique provides a mean normal direction $n=(0.64,0.15,0.76)(\mathrm{GSM})$. The ratio of intermediateto-minimum MVA eigenvalues is $>10$. 


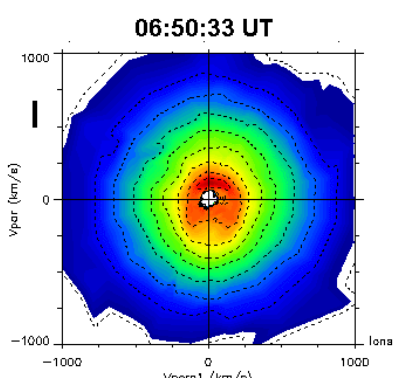

07:29:07 UT

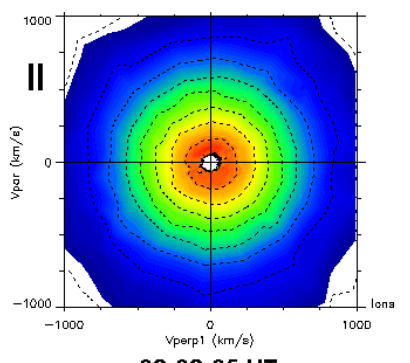

08:08:05 UT

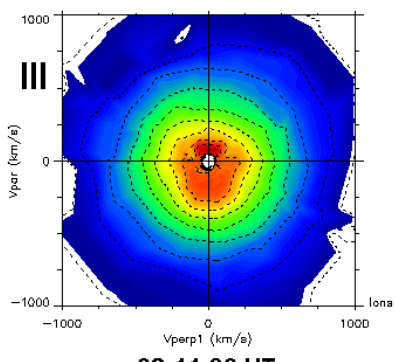

08:11:30 UT

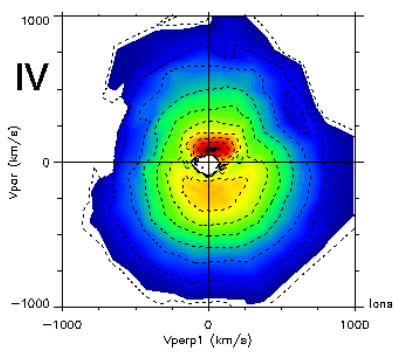

08:12:06 UT

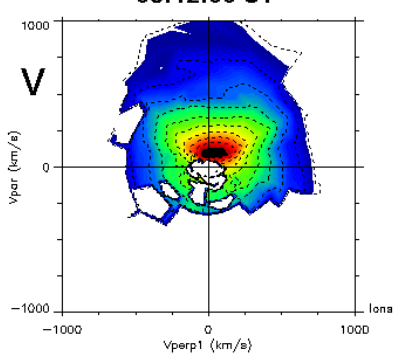

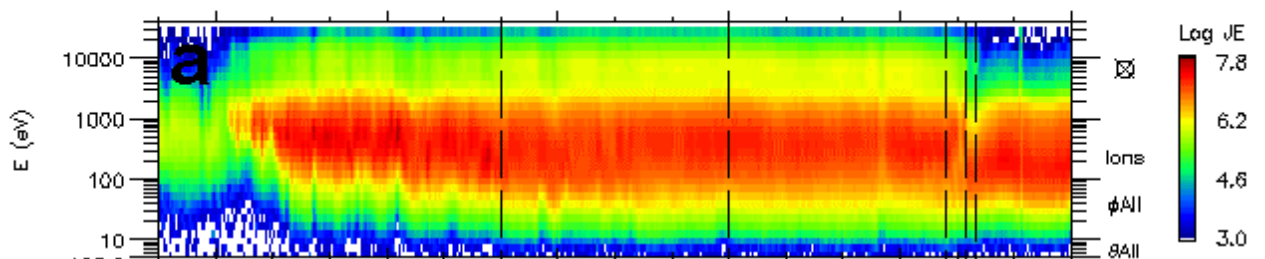
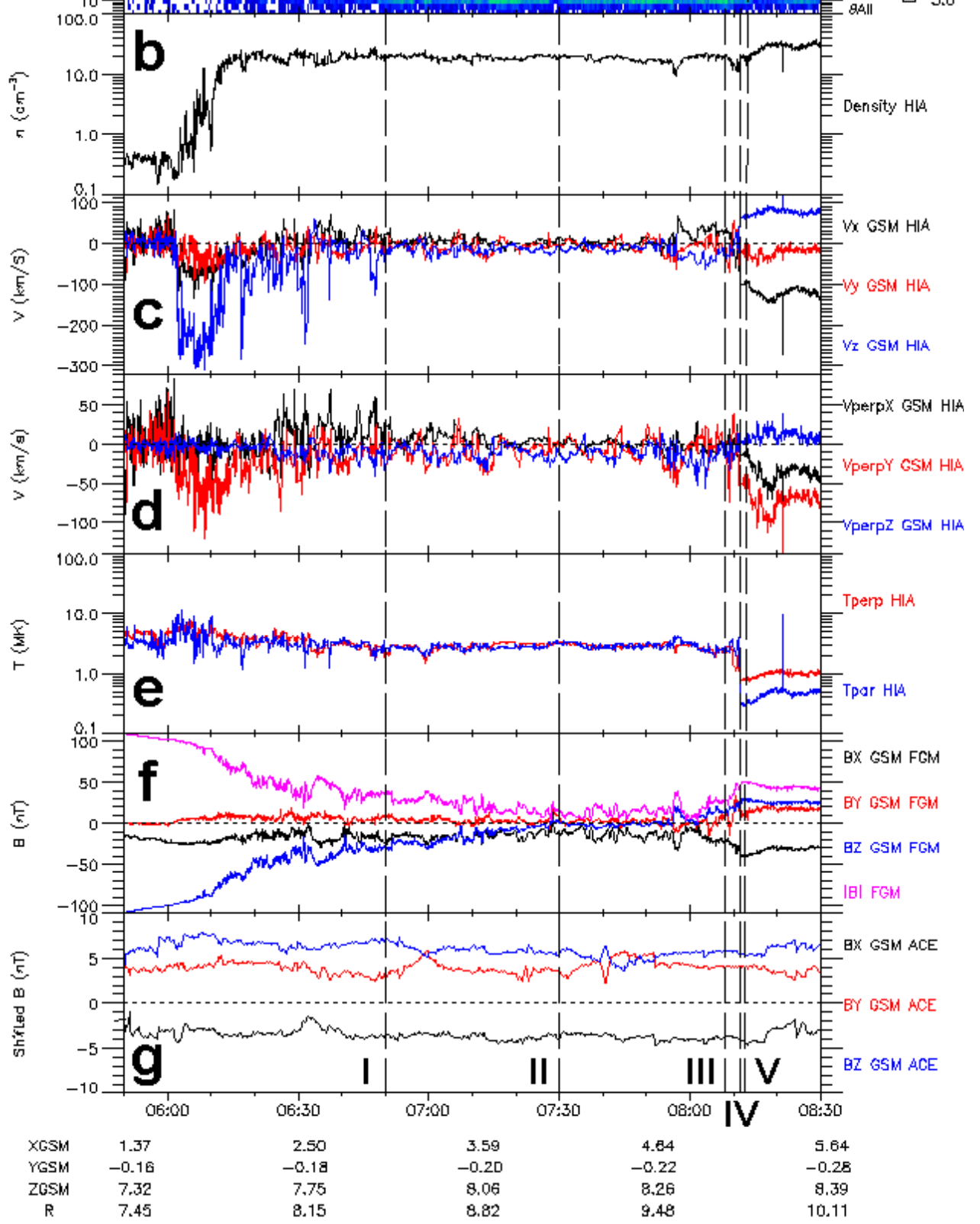

Fig. 2. This plate shows combined CIS, FGM and ACE IMF data. The first panel (a) shows the ion spectrogram from the CIS/HIA instrument. Panel (b) shows the density from HIA. The ion bulk velocity in displayed in panel (c) while the velocity perpendicular to the magnetic field (the convection velocity) is shown in panel (d) (both in GSM coordinates). Panel (e) presents the parallel and perpendicular (assuming gyrotropy) temperatures in Mega Kelvin (MK). Panel (f) displays the FGM magnetic field components in GSM and its modulus. Panel (g) shows the IMF monitored by the ACE spacecraft. The data have been time shifted according to correlation with FGM data in the adjacent magnetosheath. Below the panel composer, the position of the spacecraft in GSM coordinates is displayed for five different times. On the left side of the plate are displayed 5 distribution functions of interest. They are taken at five different times and are in the form of cuts through the $\left(V_{/ /}, V_{\perp}\right)$ plane. These are displayed in the spacecraft frame so that, for example, the bulk flow observed in the magnetosheath $(V)$ contrasts with the isotropic and stagnant nature of the SEC (II). 
Table 1. This table presents the results arising from the application of the Minimum Variance Analysis (MVA) technique on the SEC/Magnetosheath boundary for the three events and for the four spacecraft in GSE coordinates (no data is available on SC 2 on 21/03/2002). The data interval used for the analysis is given. The ratio of minimum to intermediate eigenvalues is given for each spacecraft, as well as the average. The average normal direction is also given, both in GSE and GSM coordinates.

\begin{tabular}{|c|c|c|c|c|}
\hline \multirow[t]{2}{*}{$16 / 03 / 2002$} & \multirow{2}{*}{$\begin{array}{c}\text { Interval: } \\
\lambda_{2} / \lambda_{3}\end{array}$} & \multicolumn{3}{|c|}{ 08:06:00 - 08:14:00 UT } \\
\hline & & $\mathrm{n}_{\mathrm{X}}(\mathrm{GSE})$ & $\mathrm{n}_{Y}(\mathrm{GSE})$ & $\mathrm{n}_{\mathrm{Z}}(\mathrm{GSE})$ \\
\hline SC 1 & 13.2 & 0.63 & 0.32 & 0.70 \\
\hline SC 2 & 12.7 & 0.65 & 0.35 & 0.68 \\
\hline $\mathrm{SC} 3$ & 8.4 & 0.66 & 0.39 & 0.64 \\
\hline $\mathrm{SC} 4$ & 11.7 & 0.63 & 0.32 & 0.76 \\
\hline Mean (GSE) & 11.5 & 0.642 & 0.345 & 0.695 \\
\hline Mean (GSM) & & 0.642 & 0.146 & 0.761 \\
\hline \multirow[t]{2}{*}{$21 / 03 / 2002$} & Interval: & \multicolumn{3}{|c|}{ 02:08:30 - 02:11:30 UT } \\
\hline & $\lambda_{2} / \lambda_{3}$ & $\mathrm{n}_{\mathrm{X}}(\mathrm{GSE})$ & $\mathrm{n}_{\mathrm{Y}}(\mathrm{GSE})$ & $\mathrm{n}_{\mathrm{Z}}(\mathrm{GSE})$ \\
\hline SC 1 & 2.1 & 0.72 & -0.01 & 0.69 \\
\hline SC 2 & $\mathrm{x}$ & $\mathrm{x}$ & $\mathrm{x}$ & $\mathrm{x}$ \\
\hline $\mathrm{SC} 3$ & 1.7 & 0.77 & 0.17 & 0.62 \\
\hline $\mathrm{SC} 4$ & 2.0 & 0.74 & 0.07 & 0.66 \\
\hline Mean (GSE) & 1.93 & 0.743 & 0.083 & 0.657 \\
\hline Mean (GSM) & & 0.743 & -0.260 & 0.609 \\
\hline \multirow[t]{2}{*}{$23 / 03 / 2002$} & Interval: & \multicolumn{3}{|c|}{$11: 36: 50-11: 37: 50$ UT } \\
\hline & $\lambda_{2} / \lambda_{3}$ & $\mathrm{n}_{\mathrm{X}}(\mathrm{GSE})$ & $\mathrm{n}_{\mathrm{Y}}(\mathrm{GSE})$ & $\mathrm{n}_{\mathrm{Z}}(\mathrm{GSE})$ \\
\hline SC 1 & 3.3 & 0.67 & -0.73 & 0.10 \\
\hline $\mathrm{SC} 2$ & 3.0 & 0.64 & -0.76 & 0.10 \\
\hline SC 3 & 2.8 & 0.65 & -0.75 & 0.08 \\
\hline $\mathrm{SC} 4$ & 2.7 & 0.63 & -0.77 & 0.09 \\
\hline Mean (GSE) & 2.95 & 0.647 & -0.752 & 0.092 \\
\hline Mean (GSM) & & 0.647 & -0.753 & -0.083 \\
\hline
\end{tabular}

The boundary mean normal speed is deduced from the application of the Planar Discontinuity Analysis technique (planar-DA) (Dunlop et al., 1997; Dunlop et al., 2003). This method uses the timings of the boundary crossings at each of the four spacecraft and compares it to the inter-spacecraft relative distance along the mean normal direction (over the four spacecraft), estimated through the MVA analysis. It allows an estimate of both normal speed and acceleration, but only the average normal speed is mentioned in this paper. The technique yields a normal velocity $\sim-10 \mathrm{~km} / \mathrm{s}$ for the boundary on 16/03/2002. The negative sign of this normal speed is consistent with an outbound crossing of the boundary. With a normal boundary speed of $-10 \mathrm{~km} / \mathrm{s}$ and a current sheet crossing duration of $\sim 113 \mathrm{~s}$, the boundary thickness is $\sim 1130 \mathrm{~km}(\sim 70$ thermal magnetosheath ion gyroradii).

We have estimated the normal flow component across the boundary from the ion measurements. However, this normal flow is of the order of the boundary normal speed on average (and negative, i.e. inward), which does not allow a direct confirmation of possible plasma entry through the boundary.

During this event, the IMF was particularly steady and oriented northward and duskward, with a mean clock angle $\left(\tan ^{-1}\left(B_{y} / B_{z}\right)\right)$ of $\sim 35^{\circ}$ (panel (g) of Fig. 2). Cluster observed, between 08:11 and 08:20 UT, a plasma depletion layer (PDL) (Zwan and Wolf, 1976) characterized by an increase in the magnetic field, a decrease in the density (Crooker et al., 1979) and a decrease in both the parallel and perpendicular temperatures (Paschmann et al., 1993) (panels (b), (e) and (f)). In addition, a slight decrease in bulk flow velocity is observed in the PDL on approach to the SECmagnetosheath boundary from the outside (panel (c)). We display a distribution function $(V)$ in this region just adjacent to the boundary in Fig. 2.

In summary, under conditions of steady northward IMF with finite $B_{y}$ (clock angle $\sim 35^{\circ}$ ), the large-scale cusp structure appeared consistent with plasma injection occurring at the magnetopause in the lobes, with a global sunward convection present within the region. A stagnant exterior cusp was observed where no sign of large-scale eddies or vortices in the flows and fields were apparent. A relatively sharp boundary separates the SEC from the magnetosheath. A PDL was observed on the magnetosheath side of this boundary. Overall, this event confirms the findings of paper 1 for such similar IMF conditions.

\subsection{The $21 / 03 / 2003$ event}

The Cluster data and analysis plots for the 21/03/2002 event are shown in Figs. 3 and 5b, in a similar format to those presented for the previous event. As we describe this and the next event, we will focus on the similarities and differences with the first one and that of paper 1 .

\subsubsection{Overview}

In Fig. 3, at 00:00 UT, the Cluster fleet was in the plasma mantle rather than in the tenuous lobes, as in the previous event. It is characterized by upward (mainly) and tailward flowing ions (panel (c)), which is typical of the plasma mantle region (Rosenbauer et al., 1975). The IMF was southward as seen in panel $(\mathrm{g})$ at that time. These conditions lasted until 00:45 UT, when a velocity shear was observed at Cluster. The spacecraft began to sample a region that contained both up- and down-flowing ions (note the presence of jet features at 00:45 and 00:50 UT) and the velocities were lower. This transition was well correlated with an IMF turning from sunward and duskward to mainly northward at $~ 00: 47$ UT in panel $(\mathrm{g})$.

From then on, the data show similar properties to the previous event (and paper 1), after the high-speed, downward plasma flows. The SEC region was sampled between 01:20 UT and 02:10 UT and was characterized by low flow speed, isotropic ion distributions and a weak magnetic field. The convection there is again very low and 

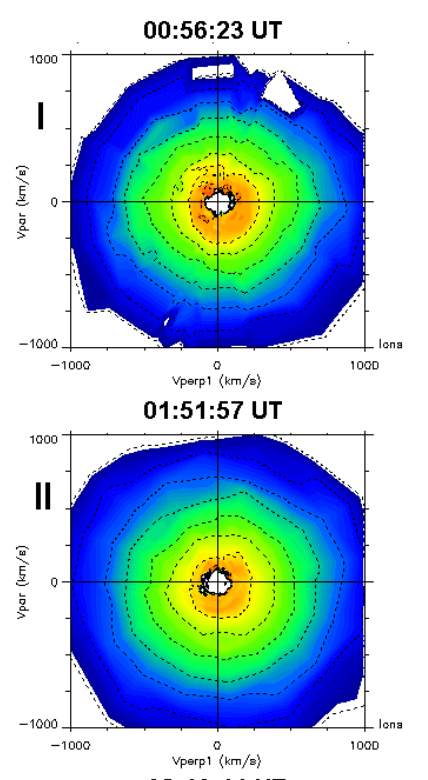

02:10:14 UT

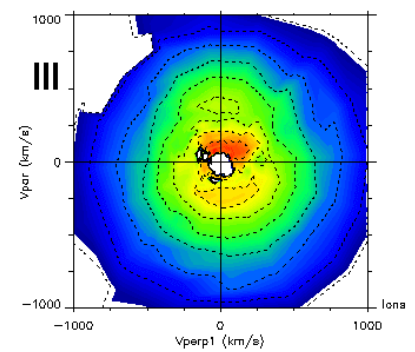

02:10:30 UT
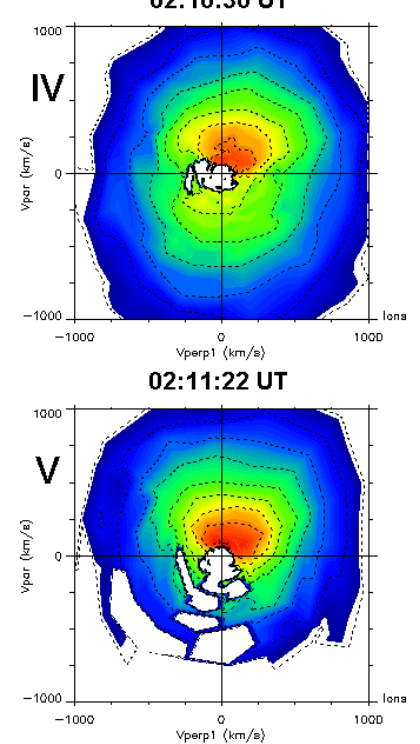

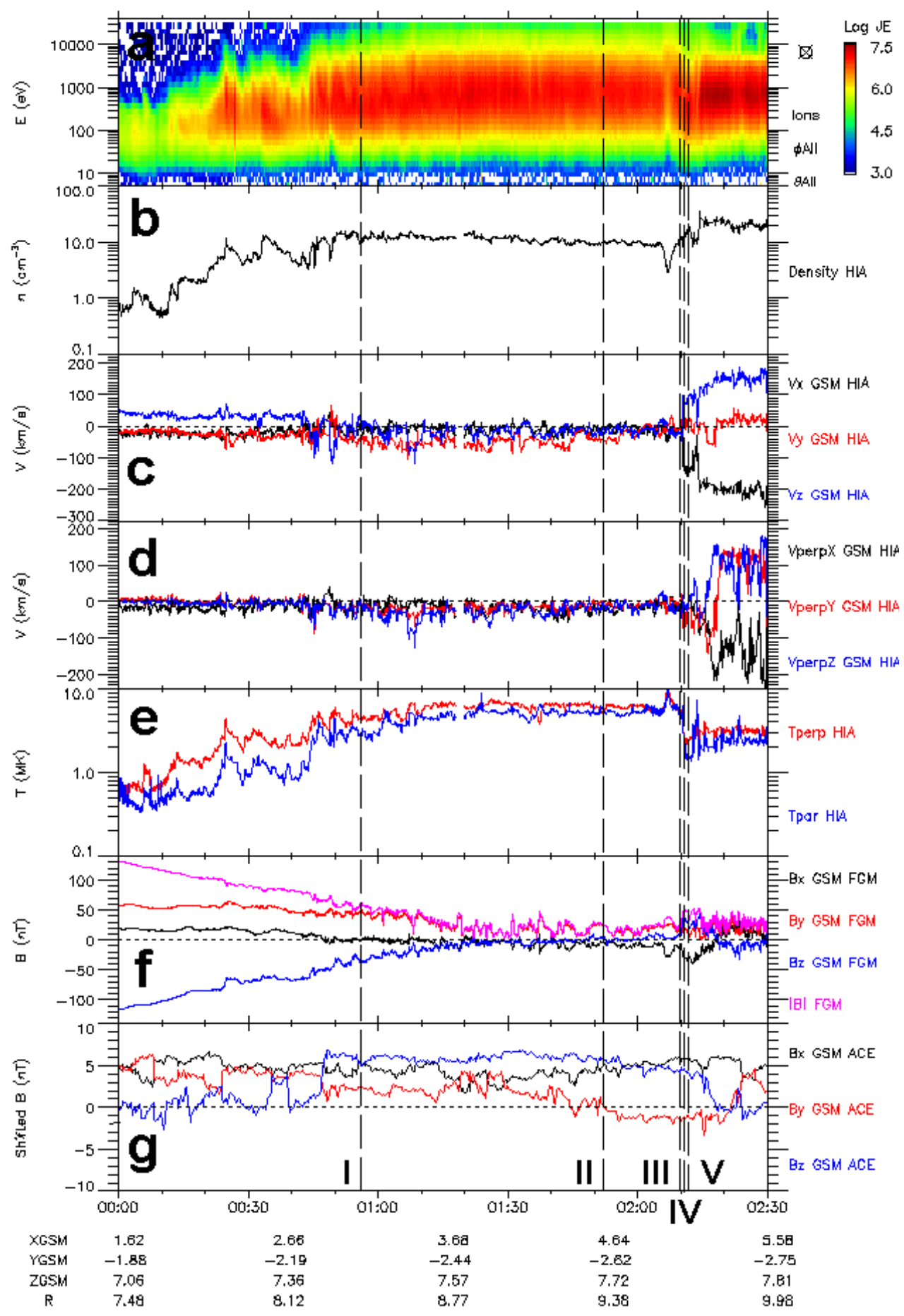

Fig. 3. Distributions and panel composer plot of Cluster data for the 21/03/2002 event. See the caption of Fig. 2.

directed downward and dawnward (panel (d)). The various distributions shown are sampled in similar regions as for the 16/03/2002 event and display an equivalent behavior. Finally, a PDL is observed adjacent to the SEC-magnetosheath boundary between 02:10 and 02:13 UT (panels (b) and (f)), and it is again characterized by a decreased bulk velocity as compared to the magnetosheath proper.

\subsubsection{IMF characteristics}

The IMF was mainly northward during the entire SEC crossing; it had a finite duskward component until $\sim 01: 30$ UT and gradually evolved towards a predominantly northward $\left(B_{y} \sim 0, B_{z}>0\right)$ orientation around 02:00 UT near the exit into the magnetosheath (panel $(\mathrm{g})$ ). The IMF however turned 

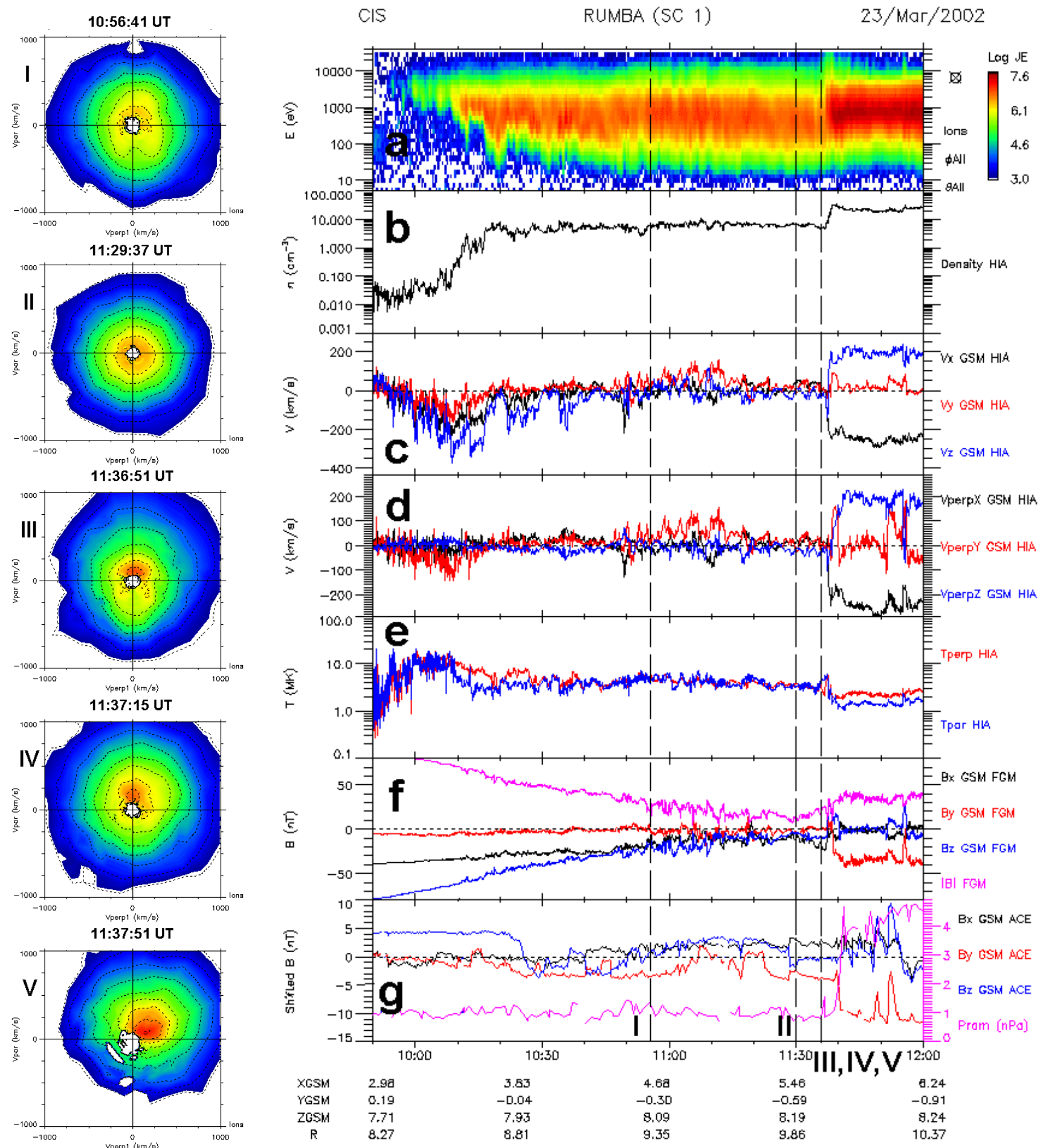

Fig. 4. Distributions and panel composer plot of Cluster data for the 23/03/2002 event. See the caption of Fig. 2.

back to a radial orientation at $02: 15 \mathrm{UT}$ (with a weak $B_{z}$ component). This IMF turning is clearly correlated with FGM data in terms of the $B_{z}$ component (blue curve in panel (f)) when the spacecraft just exited in the magnetosheath (02:1502:20 UT). The SEC-magnetosheath boundary was therefore crossed prior to it, at 02:10 UT.

\subsubsection{Boundary analysis}

The SEC-magnetosheath boundary (at 02:10 UT) is again abrupt. For instance, the temperature jumps by a factor of $\sim 3(\sim 2)$ for $T_{/ /}\left(T_{\perp}\right)$ (from the magnetosheath to the SEC). MVA technique reveals a mean normal $n=(0.74,-0.26,0.61)$ in GSM (see Table 1). The eigenvalue ratio is around 2. 

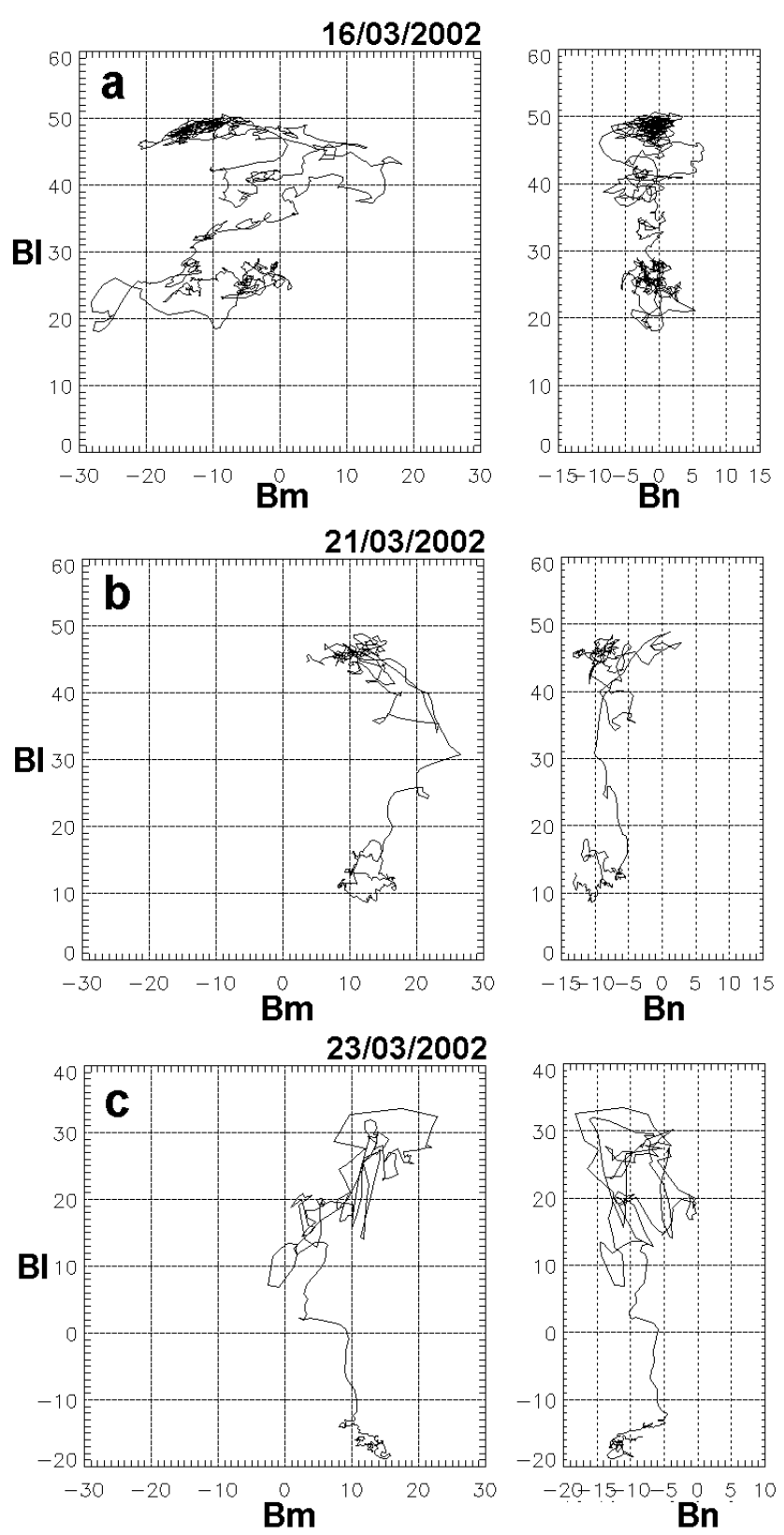

Fig. 5. Magnetic hodograms of the exterior cusp-magnetosheath boundary for all three events. The LMN coordinates directly arise from the Minimum Variance Analysis (MVA).

No Cluster data is available on spacecraft 2 for this period. However, the planar-DA technique may be used with only three spacecraft and yields a rough boundary normal speed of $\sim-25 \mathrm{~km} / \mathrm{s}$. The boundary crossing was $20 \mathrm{~s}$ long; the boundary thickness is thus $\sim 500 \mathrm{~km}(\sim 18$ thermal magnetosheath gyroradii). The hodogram of Fig. $5 \mathrm{~b}$ shows a huge normal component across the boundary of $-7 \mathrm{nT}$ and a semicircle pattern in the $\left(B_{l}, B_{m}\right)$ plane. Plasma normal flow has been estimated but is again of the order of the boundary normal speed.

\subsection{The 23/03/2002 event}

For this event, the data are displayed in Figs. 4 and 5c, again, in similar format to the previous events.

\subsubsection{Overview}

This case is similar to the 16/03/2002 event (and 04/02/2001 in paper 1) in nearly all respects. Large downward flows are first observed at the lobe-cusp boundary. A long (compared to the $16 / 03 / 2002$ event) energy-time dispersion was observed between 10:00 and 10:50 UT (according to the low-energy cut-off evolution), within which are embedded few smaller-scale injections (for example, at 10:12 and 10:20 UT). A gradual evolution is globally seen in all the parameters and the descriptive SEC region was sampled between $\sim 11: 15$ UT and 11:37:30 UT. The distribution functions shown are similar to previous events and plasma convection was again much lower inside the SEC. Its orientation was rather duskward, sunward and downward (panel (d)). The spacecraft exited into the magnetosheath at 11:37:30 UT through a sharp boundary. For this event, no PDL is observed on the magnetosheath side of this external boundary.

\subsubsection{Solar wind characteristics}

The IMF was slightly variable during the interval (panel (g)). While the $B_{z}$ component was generally positive, $B_{y}$ was usually not negligible. The SEC was therefore sampled under various IMF orientations. During the interval 11:30-11:40 UT, ACE monitored clock angles as large as $\sim 90^{\circ}$. At the SEC-magnetosheath boundary at 11:37:30 UT, the magnetic field at Cluster turned northward and slightly duskward for about one minute (panel (f)). Shortly after this exit, at 11:38:30 UT, FGM measured a rotation towards dawn which is correlated with an IMF turning seen at ACE $\left(B_{z}\right.$ and $B_{y}$ components). Therefore, this IMF turning was observed at Cluster when the spacecraft were already in the magnetosheath. As additionally shown in panel (g) (superimposed magenta curve), this IMF rotation (at 11:38:30 UT) coincided with an abrupt increase in the solar wind dynamic pressure by a factor of $\sim 4$. The variations of the solar wind conditions may account for the absence of the PDL in this case.

\subsubsection{Boundary analysis}

The SEC-magnetosheath boundary was again abrupt (the temperature jump is $\sim 2$ for $T_{/ /}$and $\sim 1.5$ for $T_{\perp}$, from the magnetosheath to the SEC). The MVA technique yields a mean normal direction $\mathrm{n}=(0.65,-0.75,0.08)$ in GSM (Table 1). In Fig. 5c the hodogram shows a large $B_{n}$ component $(\sim-10 \mathrm{nT})$ through the boundary. The eigenvalue ratio is around 3 . The semicircle pattern in the $\left(B_{l}, B_{m}\right)$ plane of the hodogram is similar to the one of the $21 / 03 / 2002$ event but it displays a reversed sense of rotation. The use of the Planar DA technique reveals that the MVA normal is inconsistent with the inter-spacecraft distances along the normal and 


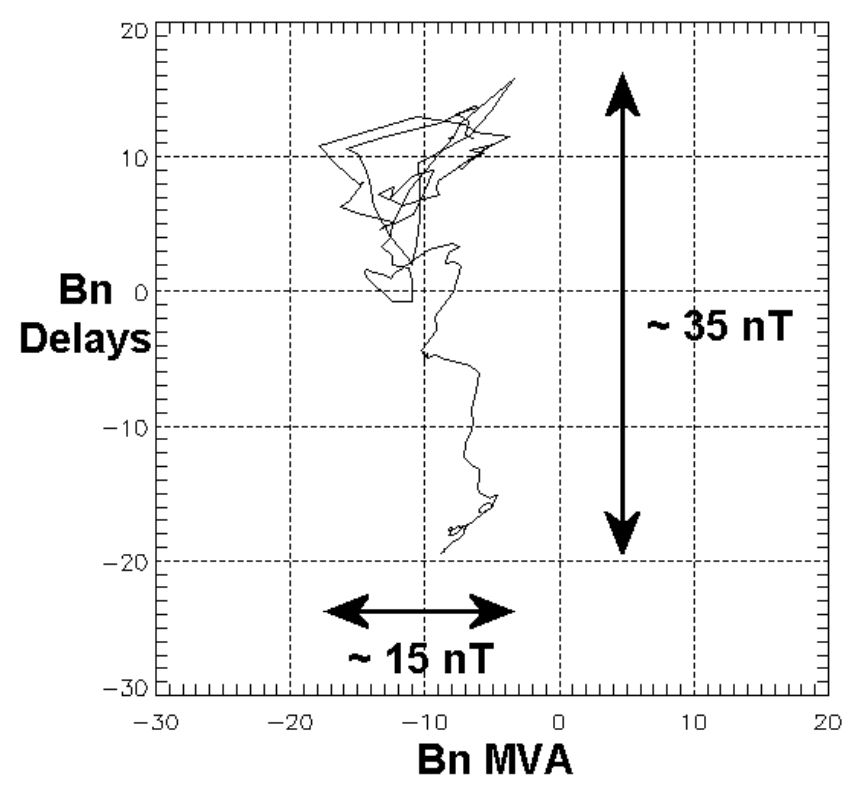

Fig. 6. This figure shows a hodogram-type plot of the normal magnetic field components arising from the MVA and time-delay techniques against each other, for the SEC-magnetosheath boundary on $23 / 03 / 2002$. It appears that the multi-spacecraft time-delay technique yields a very variable normal field component that changes greatly, particulary regarding the sign, across the boundary while the component arising from MVA is much less variable and persistently negative.

the crossing times for this boundary, possibly owing to either accelerations or bad normal determination (see Dunlop et al., 2003). We therefore complementarily determine the boundary normal vector and normal velocity based on the Harvey (1998) delay technique, assuming constant velocity without any a priori use of the MVA normal direction. It reveals a normal $\mathrm{n}=(0.82,-0.08,0.55)(\mathrm{GSM})$ and a speed of $\sim-125 \mathrm{~km} / \mathrm{s}$. This highly dynamic nature is thus possibly at the origin of the difference between the two methods (panel (g) of Fig. 4). With such a speed, this boundary is $\sim 2500 \mathrm{~km}$ thick using a crossing duration of $20 \mathrm{~s}(\sim 60$ thermal magnetosheath gyroradii).

In order to evaluate which of the two normal orientations is most representative of the boundary, we plot the magnetic field normal components arising from each technique against each other in Fig. 6. It is seen in this figure that not only is the variation of the amplitude lowest for the MVA normal (which is expected), but this normal shows a persistent negative magnetic component across the boundary while the magnetic component arising from the delay technique (Harvey, 1998) changes sign abruptly. It is concluded that the normal arising from MVA may be more appropriate and the negative magnetic normal component across the boundary may be reliable.

\section{Discussions}

In this section we will discuss the implications of our observations for the processes operating in the exterior cusp and its boundaries. In the first three subsections we address the characteristics of the plasma flows at the poleward edge of the cusp that appear to evolve gradually until the stagnant exterior cusp (SEC). We then discuss the structure and magnetic topology of the exterior cusp and its boundary with the magnetosheath under such northward IMF conditions. We give new insights into the actual location and characteristics of the SEC-magnetosheath boundary. We comment on its possible nature and on the effects of the presence of a PDL. We discuss the electron behavior in Sect. 4.6. The question of the magnetopause definition in this region will also be addressed.

\subsection{Flow characteristics in the high-altitude cusp}

The plasma flows observed on 16/03/2002 and 23/03/2002 at the poleward edge of the cusp were very similar to those observed on 04/02/2001, and presented in paper 1 . These were characterized by a high downward speed. On both $16 / 03 / 2002$ and 23/03/2002, the large-scale decrease in the low-energy cutoff of the ions corresponds to latitudinal energy dispersion (and in paper 1). Also, in these cases, shortlived injections are observed at smaller scales and are characterized by short, purely temporal, pitch angle (not shown) and energy-time dispersions (Vontrat-Reberac et al., 2003). Therefore, we may conclude that, although the plasma penetration rate is possibly time varying, plasma penetration may be continuous. Evidences for continuous reconnection at the high-latitude magnetopause have recently been given by Frey et al. (2003) on the basis of proton aurora precipitation (see also Phan et al. (2003) for a Cluster-IMAGE conjunction). These characteristics are compatible with reconnection occurring above the spacecraft location (at the magnetopause near the lobes), combined with a large-scale sunward convection accounting for the latitudinal dispersion (Smith and Lockwood, 1996; Sibeck et al., 1999).

On 16/03/2002 and 04/02/2001, the flow convection was downward but predominantly in the dawnward direction while the monitored IMF had a duskward component. The case of 23/03/2002 is less clear since the flow convection had a large dawnward component while the monitored IMF $B_{y}$ was close to zero. Nevertheless, such an anti-correlation between the dawn-dusk component of the flows and of the IMF, if a general trend, would be compatible with expectations from reconnection, since the $\boldsymbol{J} \times \boldsymbol{B}$ force exerted at the kink of merged field line implies such a deflection.

The 21/03/2001 event does not show any strong flow signature at the poleward edge of the cusp. But it is noted that until 00:45 UT, the IMF was southward and tailward convection was present in the plasma mantle. At 00:45 UT, the IMF turned northward, and the convection within the cusp turned to the downward direction, which is equivalent to equatorward, reversed convection. These observations 
provide further evidence that such large downward flows at the poleward edge of the cusp are only present under northward IMF, which is expected from lobe reconnection.

\subsection{Plasma evolution through the high-altitude cusp}

The Cluster trajectory allows for the study of the gradual evolution of the plasma parameters from the high-altitude cusp (flows) to the SEC, until the final exit into the magnetosheath. The global behavior of temperature and velocity, increasing and decreasing, respectively, in all events (apart from the beginning of the 21/03/2002 event), are consistent with a largescale dispersion feature. As shown in the distribution functions number I (and in paper 1), after the interval of only down-flowing ions the transition region of the high-altitude cusp (before the SEC) usually shows anisotropic plasma with counter-streaming (precipitating and reflected) ion populations.

The isotropic plasma inside the SEC results from the presence of two populations, one incoming and the other outgoing. The possibility that the distributions I in all events eventually evolve into the distributions II would support this interpretation (Fuselier et al., 2000a), and it is possible that wave-particle interaction may provide substantial ion scattering in this region (Nykyri et al., 2003). Throughout the whole interval, from the large flows up to the SEC, all variations look gradual without showing clear boundaries that could be expected if a detached region existed. The temperature levels off to the SEC value in a consistently smooth way. Such behavior emphasizes the probable non-detached nature of the descriptive SEC, and rather that it is the extension of the cusp at high altitudes (Russell, 2000), under northward IMF conditions.

\subsection{Properties of the Stagnant Exterior Cusp (SEC)}

The events analyzed here show a wide stagnant exterior cusp; it lasts for about $1 \mathrm{~h}$ on $16 / 03 / 2002$, which corresponds to an extent of over $1.5 R_{E}$ along the spacecraft trajectory. Both the magnetic field and plasma flow are particularly low there. They present some fluctuations, indicative of a possible wavy/turbulent nature at times. It must be mentioned that the ULF $(\sim 0.5-10 \mathrm{~Hz}$ from the STAFF instrument) magnetic wave power is low in the SEC while much enhanced in the large downward flows at the beginning of the intervals on $16 / 03 / 2002,23 / 03 / 2002$, as well as on 04/02/2001 (paper 1) (N. Cornilleau-Wehrlin, private communication). However, a systematic study of waves and turbulence in this region is beyond the scope of this paper.

The region is possibly similar to the "stagnation region" of Haerendel et al. (1978), but because it appears to be part of the cusp, the term "exterior cusp" may be more adapted. Also, the data show the exterior cusp as a large region, unlike the "plasma balls" reported by Savin et al. (2002). It is unclear how the exterior cusp (stagnant) studied here relates to the different regions described by Savin et al. (2004). The flows in the SEC show both little parallel and perpendicular (convection) components. The stagnant nature of the exterior cusp seems to persist under steady northward IMF.

Vasyliunas (1995) pointed out that plasma stagnation is unlikely to occur in the exterior cusp if magnetosheath plasma has entered the region via an RD created at the magnetopause in the sub-solar region, i.e. for southward IMF. The plasma in the exterior cusp should then be convected at a speed attaining a non-negligible fraction of the external magnetosheath flow. However, for northward IMF and lobe reconnection, very slow sunward convection may be expected in the exterior cusp and is actually clearly observed here. Moreover, the deHoffmann-Teller frame was shown to move very slowly sunward and downward at the exterior cusp-magnetosheath boundary in paper 1 , a characteristic also found and discussed later for some of the present events. In other words, the region is stagnant in terms of relative convectional behavior as compared to the adjacent magnetosheath and with respect to its isotropic nature, resulting from the mixing of incoming and outgoing ions.

The present study shows that the SEC may be present even when a substantial IMF $B_{y}$ component is monitored, with clock angles as large as $\sim 90^{\circ}$. In contrast, Cargill et al. (2004) recently showed the presence of large tailward flows in this region for southward IMF. Future studies will focus on the statistical properties of the flows in this region.

\subsection{The SEC-magnetosheath boundary characteristics}

The SEC-magnetosheath boundary studied in this paper appears to be a spatial structure since it is similarly sampled on all operating spacecraft for the three events (and paper 1). It is located at $\sim 12 R_{E}$ geocentric distance for the 04/02/2001 event of paper 1 while around $10 R_{E}$ for the present three events. No net inflow could be properly determined in the present cases but a persistent, inward normal magnetic field is observed.

We have additionally performed deHoffmann-Teller (deH-T) analysis and Walén test at the three boundaries (Sonnerup et al., 1987). Figure 7 displays the results for the 21/03/2002 and 23/03/2002 events. The deH-T velocity $\left(\boldsymbol{V}_{h t}\right)$ is shown, together with the slope and correlation coefficient of the deH-T analysis and Walén test, the data interval used for the computation and the reference pressure anisotropy (alpha) values in the magnetosheath.

Although the deH-T velocity was constantly (by varying the data interval) found to be low and directed sunward and downward for the boundary observed on 16/03/2002, no proper deH-T frame could be found so that the correlation coefficient would exceed 0.65 . Therefore, we do not show the result of the deH-T analysis and of the Walén test for this event. A reason for this failure may be related to temporal variations during the interval of boundary crossing, while the deH-T analysis requires a stationary boundary.

A good deH-T frame was found for the 21/03/2002, with a slope of 1.00 and a correlation coefficient of 0.94 . The deH$\mathrm{T}$ velocity is low and shows components directed downward and sunward, as for the 04/02/2001 event studied in paper 1 . 
This is compatible with the low convection observed in the SEC and with a lobe reconnection topology. It implies for instance that the field lines connecting the two region were convected towards the spacecraft from above and behind (according to their trajectory), thus from the high-altitude lobe region (refer to Fig. 8).

The computation of $\boldsymbol{V}_{h t}$ further allows an independent estimation of the boundary normal velocity. If one were to obtain the boundary normal speed from $\boldsymbol{V}_{h t} \cdot \boldsymbol{n}$, a boundary normal speed of $\sim-31 \mathrm{~km} / \mathrm{s}$ is found for the $21 / 03 / 2002$ event, which is consistent with that determined through multispacecraft analysis and for an outward crossing of the boundary. While the Walén test cannot be performed properly for the $16 / 03 / 2002$ event, the analysis of the boundary observed on 21/03/2002 shows a high, but less than unity slope $(\sim 0.7)$. Although this value is somewhat different from 1, the value expected for a pure Rotational Discontinuity (RD), it may be mentioned that a slope of 0.9 had been found in paper 1 for a similar boundary $(04 / 02 / 2001)$.

A good deH-T frame was also found in the case of the 23/03/2002 SEC-magnetosheath boundary, with a slope of 0.99 and a correlation coefficient of 0.97 (Fig. 7b). The deH$\mathrm{T}$ velocity is again pointing downward, thus consistent with an equatorward convection. However, a large anti-sunward component is estimated. As noted below, this characteristic probably arises from the arrival of an interplanetary shock (solar wind pressure enhancement).

The Walén test performed in this case reveals a great discrepancy between the plasma velocity and the local Alfvén speed across the boundary. Note that the slope of $\sim 1.5$ is very sensitive to the data interval chosen and should not be given any particular meaning. Despite this, we noted that deH-T analysis was successful. The subsequent inferred normal velocity of the boundary is $\boldsymbol{V}_{h t} \cdot \boldsymbol{n}=-91 \mathrm{~km} / \mathrm{s}$ and is consistent with the high speed of $\sim-125 \mathrm{~km} / \mathrm{s}$ obtained previously. The high solar wind dynamic pressure exerted on the boundary at this time (as monitored by ACE) is also a possible explanation for the Walén test failure. This might have resulted in unbalanced pressure across the boundary. It must finally be noted that these results are similar when using the data from spacecraft 3 and 4 (the inter-spacecraft distance was of $\sim 100 \mathrm{~km}$ ).

The results from the deH-T analysis and Walén tests performed on the SEC-magnetosheath boundary for the three events studied here and for that of paper 1 reveal common features. They suggest that plasma and field parameters sampled through the discontinuity are in accordance with the global convection in the exterior cusp being low and directed downward and sunward. The rotational-like nature of each boundary, already revealed through the MVA analysis (negative $B_{n}$ ), is reinforced via the complementary Walén test in the case of the $04 / 02 / 2001$ (paper 1), and partially on $21 / 03 / 2002$. However, it is apparent that the exact nature of this boundary (possibly a RD) will deserve further investigation.

In addition, the positive slope of the Walén relations indicates that the normal magnetic component across the discon-

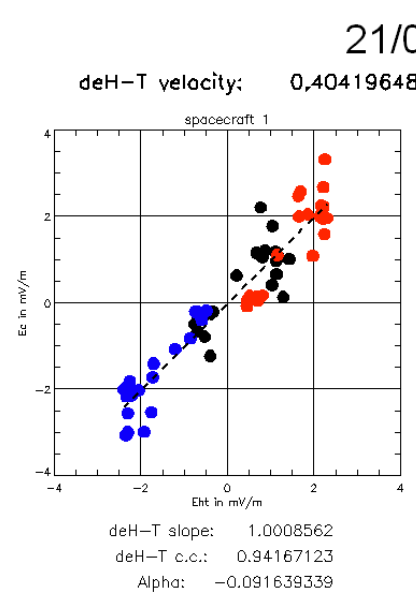

$21 / 03 / 2002$

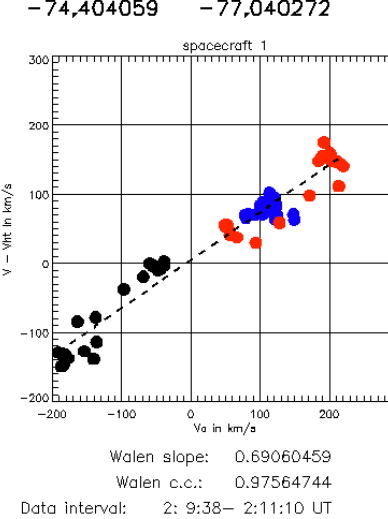

$23 / 03 / 2002$
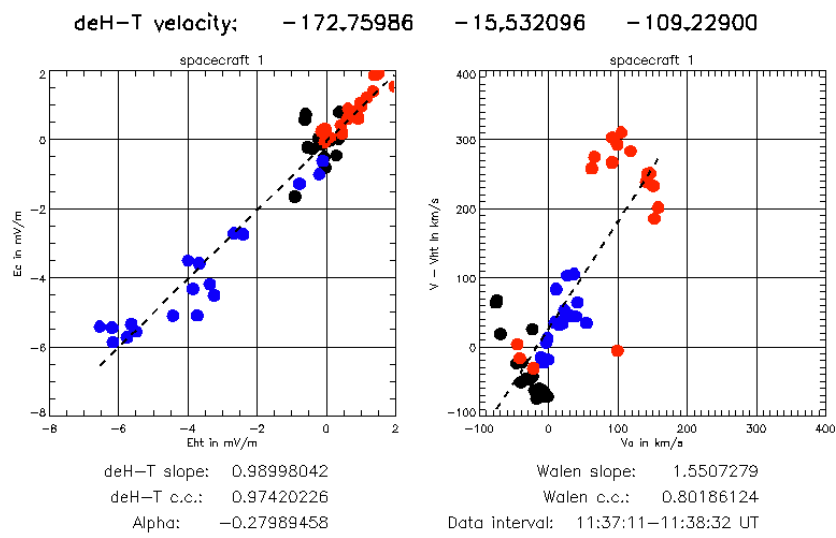

Fig. 7. Scatter plots of the deH-T analysis and Walén tests for the two 21/03/2002 and 23/03/2002 events (GSM coordinates). The Walén test for the 23/03/2002 event totally fails, possibly owing to the high solar wind pressure increase monitored by ACE at that time.

tinuity points inward (for the Northern Hemisphere), which is consistent with the results from MVA and the boundary being the result of lobe reconnection.

The large-scale structure and topology of the exterior cusp as inferred from our analysis is depicted in Fig. 8 in the context of lobe reconnection. There we display the schematic locations of the large plasma flows, at the poleward edge of the cusp. With increasing time, Cluster goes to lower latitudes and deeper into the exterior cusp, and gradually observes a more isotropic ion population inside the SEC. Right at the external boundary (within the magnetic field rotation), this population is observed to separate into two mixed populations: one cold, incoming and another hotter, outgoing. A low, sunward and downward deH-T velocity characterizes this boundary and a PDL is observed just adjacent to it on its magnetosheath side.

\subsection{Properties of the magnetosheath boundary layer}

In Fig. 9 we display combined CIS, FGM (for the Alfvén velocity) and PEACE data focused on the SEC-magnetosheath 


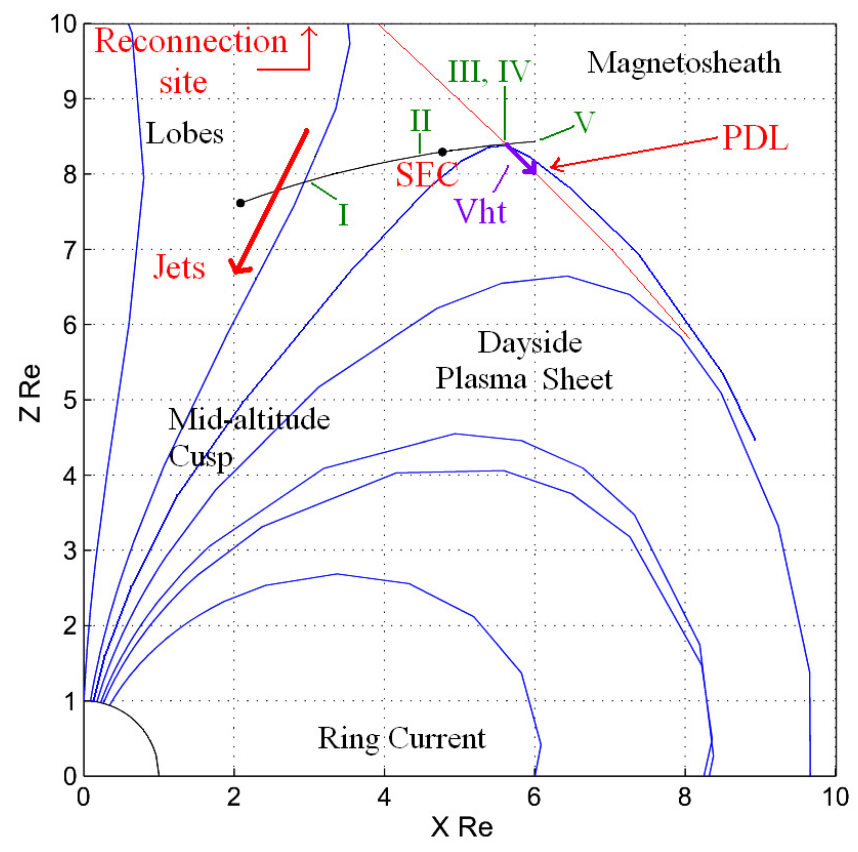

Fig. 8. Schematic of the possible large-scale topology of the exterior cusp and surrounding regions as inferred from the present analysis, in the context of lobe reconnection. High-speed downward flows are first observed at the poleward boundary with the lobes. The hot, isotropic ions are present first at lower latitudes, and later in the stagnant exterior cusp (SEC) until the spacecraft reach the external boundary. A sub-Alfvénic plasma depletion layer (PDL) is present in the magnetosheath outside the external boundary. The deH-T velocity of the boundary is oriented downward and sunward. The orbit of the Cluster spacecraft is shown for context (case of 16/03/2002), together with the rough locations where each displayed distribution function is observed. I: counter-streaming ion populations (after the large flows); II: isotropic SEC population; III and IV: separated cold, incoming, and hot, outgoing populations right at the external boundary; V: flowing magnetosheath (or PDL) population.

boundary for the $16 / 03 / 2002$ and $21 / 03 / 2002$ events. The temperature boundary (panels (d)) is highlighted by the first vertical black line. It corresponds to the beginning of the magnetic boundary (from the magnetosheath side). Directly within the boundary, the ions are shown to be very slow $(|\boldsymbol{V}|$ in panels (b)), isotropic and hot.

Outside the boundary the plasma is more typical for the magnetosheath. However, the magnetic field in this region is higher than further out in the magnetosheath (larger Alfvén speeds in panels (b)). The density (not shown) is also lower in this region, revealing the plasma depletion layer (PDL) (Zwan and Wolf, 1976) nature mentioned previously. Due to a lower magnetic field, the boundary layer is a sub-Alfvénic region (panels (b) of Fig. 9). Close to the boundary, the Alfvén Mach number approaches $\sim 0.5$. The 04/02/2001 event studied in paper 1 also shows the presence of an extended sub-Alfvénic PDL attached to the boundary on the magnetosheath side.
Although the Walén test is not perfectly successful for all the boundaries we have studied, we discuss the effects of the PDL assuming that the boundary may be formed by Alfvén waves (a RD). The sharpness of the parameter jumps as well as the deH-T velocities indeed suggest that the boundary is made of waves propagating opposite to the external magnetosheath flow in the sunward and downward direction at a speed close to the local Alfvén speed. Such a RD can thus propagate slowly sunward and downward only because of the presence of the sub-Alfvénic PDL. This behavior is only possible if the magnetosheath at the lobe reconnection site was also sub-Alfvénic. In other words, it is possible that the lobe reconnection site and the overall topology remain stable because of the presence of an adjacent sub-Alfvénic PDL outside the boundary, as envisaged by Fuselier et al. (2000b).

In addition, the ion bulk velocity is decreased in the PDL (as observed in panels (b) of Fig. 9) relative to the ion velocity in the magnetosheath proper (later times). This decrease in the flow speed on approach to the magnetopause is in contrast to the sub-solar PDL where the tangential flow speeds up (Phan et al., 1994). The decrease of flow speed in the present high-latitude events (in addition to the magnetic field increase) contributed to render the flows sub-alfvenic (see also Petrinec et al., 2003).

\subsection{Characteristics of the magnetosheath electron bound-} ary layer

The last three panels of Fig. 9 display the electron data for the same interval. The spectrograms of anti-parallel, perpendicular and parallel flowing electrons are shown from top to bottom. Inside the exterior cusp, the electrons appear hotter than in the magnetosheath for all three directions (according to the spectral width; temperature data are not available). This characteristic suggests that the electrons are heated upon entry through the boundary. Right outside and adjacent to the boundary on the magnetosheath side, one observes the presence of an electron boundary layer. It is characterized, in both events, by a longer persistence of heated magnetosheath electrons in the parallel direction. These intervals are between the two vertical black lines.

If electrons are heated upon passage through the boundary, these may reflect at low altitudes (or may directly be reflected and heated at the boundary) and then escape back into the magnetosheath through the same boundary (Onsager et al., 2001). In the context of northern lobe reconnection and northward IMF, however, such heated electrons should be detected in the anti-parallel direction, opposite to the present cases.

The origin of the heated electrons forming this layer is unclear. Based on similar observations, Onsager et al. (2001) suggested that these may originate from reconnection occurring in the lobes of the Southern Hemisphere. To first order, the negative IMF $B_{x}$ component on $16 / 03 / 2002$ seem to discredit this scenario (the positive IMF $B_{x}$ on 21/03/2002 is compatible). But the dipole tilt angle may be an equally important factor in determining which hemisphere might 


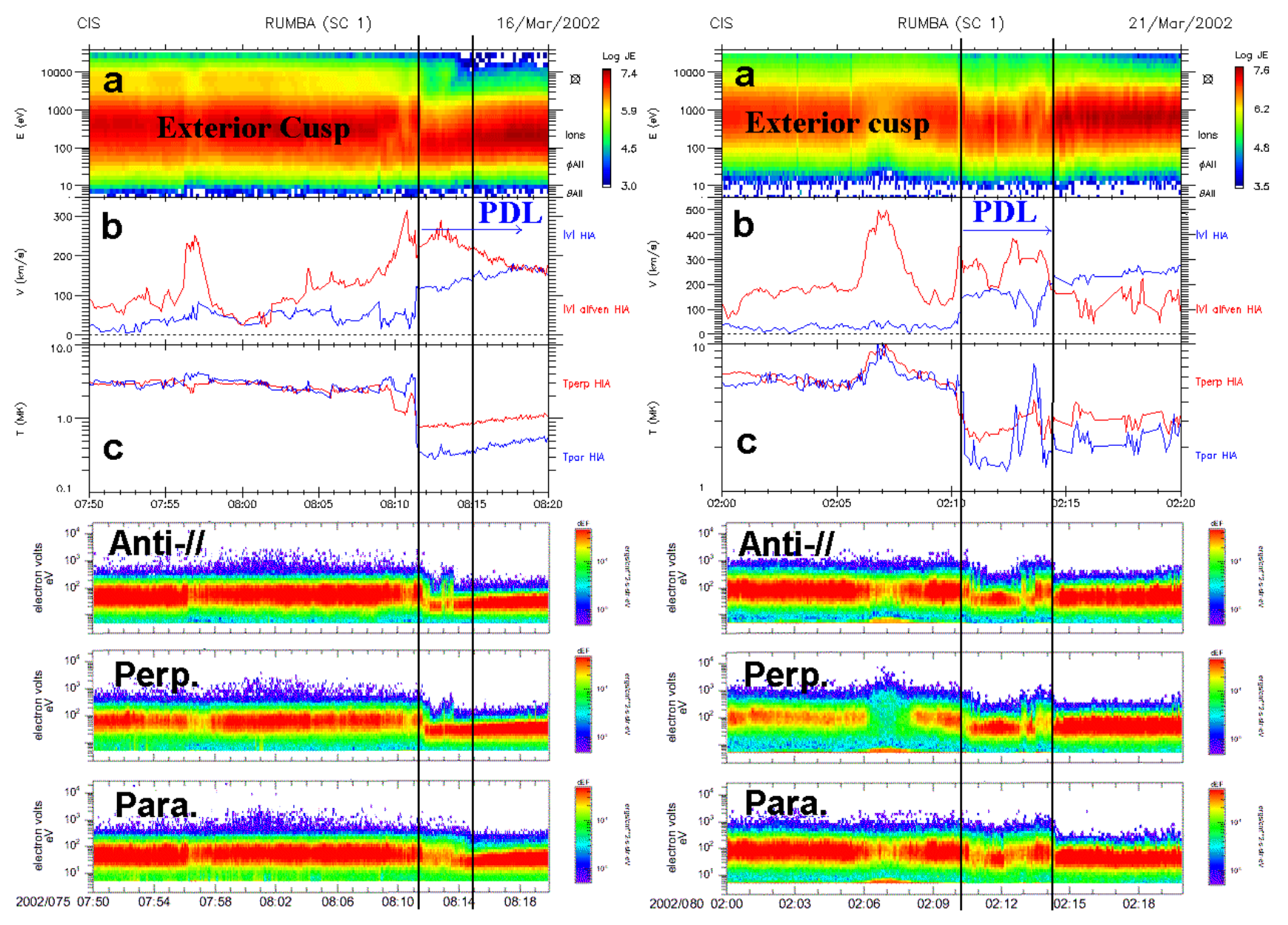

Fig. 9. Plates showing a zoom of the combined Cluster CIS, FGM and PEACE data, focused on the exterior cusp-magnetosheath boundary for two events: 21/03/2002 and 21/03/2002. Panels (a) show the spectrograms from HIA. Panels (b) show the magnitude of the HIA ion velocity together with the Alfvén speed (from FGM magnetic data). The ion temperature (parallel and perpendicular) is displayed in panels (c). Following are the electron spectrograms for the anti-parallel, perpendicular and parallel flowing electrons from the PEACE instrument for the same interval. The extents of the plasma depletion layer (PDL; shown by the blue arrow) and of the magnetosheath, heated electron boundary layer (between the two vertical black lines) are highlighted.

reconnect first. And it appears that the dipole tilt angle is suitably negative for both events, being $\sim-8.4^{\circ}$ and $-7.5^{\circ}$, respectively, for 16/03/2002 and 21/03/2002.

\subsection{Comment on the magnetopause definition}

On the basis of a statistical study, Lavraud et al. (2004) showed that the exterior cusp region is bounded by clear boundaries with the lobes, the dayside plasma sheet and the magnetosheath. They moreover highlighted that the region is in apparent equilibrium with its surroundings, and is a diamagnetic cavity (see also Tsyganenko and Russell, 1999). Because the diamagnetic effect is anti-proportional to the square of the field magnitude, the inner boundaries cannot be fully observed in the magnetic field data at lower altitude (Russell, 2000). This recalls the question of the magnetopause location and definition in the exterior cusp region. The inner boundaries of the exterior cusp form an indentation that had been called the magnetopause (Paschmann et al., 1976; Haerendel et al., 1978; Russell et al., 2000); the "exterior" cusp is exterior to the magnetopause in this case. However, if the external boundary is formed via reconnection, it may be more appropriate to define this latter as the magnetopause (Onsager et al., 2001). In that case, calling the external boundary the magnetopause would lead to the misnaming of the "exterior" cusp. The possible role of reconnection in structuring the cusp region certainly needs more exploration.

\section{Summary}

The conclusions drawn below are the result of a multi-event analysis. It was based on the selection of events occurring under steady northward IMF conditions, combined with the occurrence of a direct exit from the exterior cusp into the magnetosheath. 
- The presence of large downward flows at the poleward edge of the cusp, their convectional behavior ( $V_{\perp y}$ opposite to IMF $B_{y}$ ) and gradual evolution (dispersions) are consistent with lobe reconnection.

- The gradual transition of plasma parameters from the poleward edge of the cusp to the most distant part of the cusp (SEC) tend to show that the stagnant plasma results from the mirroring and scattering of the aforementioned plasma flows, after equatorward and sunward convection. But the possible processes acting there are still to be investigated.

- The existence of a region descriptively termed the stagnant exterior cusp (SEC) was shown on the basis of several similar events. It is present even when large IMF $B_{y}$ is monitored by the upstream ACE spacecraft (up to $90^{\circ}$ clock angle).

- The properties of the SEC-magnetosheath boundary are as follows. The boundary always has a rotational-like nature, so that the $B_{n}$ component across it is compatible with a field line connected to the magnetosheath (with northward field). The "S" shaped nature of the hodogram of the boundary, first revealed in paper 1 , is not a permanent feature. The polarization senses of the hodograms are variable. The existence of the boundary on four events and similarly sampled on the four Cluster spacecraft may prove that it is a spatial structure. A substantial heating process seems to be present at the boundary but its nature is unknown.

- The boundary has a slow deH-T velocity generally pointing sunward and downward, compatible with a discontinuity propagating from a lobe reconnection site. The rough satisfaction of the tangential stress balance (Walén test) for some events suggests that it may be a rotational discontinuity. This would further illustrate that magnetosheath plasma indeed penetrates the exterior cusp through this boundary, but more focused investigations should be made in order to determine its exact nature.

- A plasma depletion layer (PDL) is observed in three of the four events studied (with paper 1). In addition to the typical density decrease and magnetic field pile-up, a drop in the bulk flow velocity is also observed on approach to the SEC-magnetosheath boundary from its outside. The flow in the PDL is sub-Alfvénic while the magnetosheath proper is super-alfvénic. The presence of sub-Alfvénic flows at such high latitudes is consistent with being able to observe the consequences of reconnection at a location sunward of the lobe reconnection site.

- Finally, the observation of a magnetosheath boundary layer, adjacent to the boundary and containing heated electrons flowing parallel to the magnetic field, appears inconsistent with the source being reconnection in the northern lobes. However, it is not unlikely that these come from lobe reconnection in the Southern Hemisphere owing to the negative magnetic dipole tilt during the events.

Acknowledgements. The authors are grateful to the CIS, FGM and PEACE teams for their incomparable work in data processing. We thank the ACE MFI and SWEPAM instrument teams and the CDAWeb for providing the solar wind data. B. L. is grateful to
N. Cornilleau-Wehrlin, L. Rezeau and B. Grison for fruitful discussions.

Topical Editor T. Pulkkinen thanks N. F. Pisarenko and another referee for their help in evaluating this paper.

\section{References}

Avanov, L. A., Smirnov, V. N., Waite Jr., J. H., Fuselier, S. A., and Vaisberg, O. L.: High-latitude magnetic reconnection in subAlfvénic flow: Interball tail observations on May 29, 1996, J. Geophys. Res., 106, 29 491-29 502, 2001.

Balogh, A., Carr, C. M., Acuña, M. H., Dunlop, M. W., Beek, T. J., Brown, P., Fornaçon, K.-H., Georgescu, E., Glassmeier, K.H., Harris, J., Musmann, G., Oddy, T., and Schwingenschuh, K.: The Cluster magnetic field investigation: overview of in-flight performance and initial results, Ann. Geo., 19, No. 10-12, 12071217, 2001.

Cargill, P. J.: A model for plasma flows and shocks in the highaltitude cusp, J. Geophys. Res., 104, 14 647-14 653, 1999.

Cargill, P. J., Dunlop, M. W., Lavraud, B., Elphic, R. C., Holland, D. L., Nykyri, K., Balogh, A., Dandouras, I., and Rème, H.: CLUSTER encounters with the high altitude cusp : Boundary structure and magnetic field depletions, Ann. Geophys., 22, 1739-1754, 2003.

Crooker, N. U., Eastman, T. E., and Stiles, G. S.: Observations of plasma depletion in the magnetosheath at the dayside magnetopause, J. Geophys. Res., 84, 869-874, 1979.

Dungey, J. W.: Interplanetary magnetic field and the auroral zones, Phys. Rev. Lett., 6, 47-48, 1961.

Dunlop, M. W., Woodward, T. I., Southwood, D. J., Glassmeier, K.H., and Elphic, R. C.: Merging 4 spacecraft data: concepts used for analysing discontinuities, Adv. Space Res., 20, 1101-1106, 1997.

Dunlop, M. W., Balogh, A., and Glassmeier, K.-H.: Four-point Cluster application of magnetic field analysis tools: The discontinuity analyzer, J. Geophys. Res., 107, No A11, 1385, doi:10.1029/2001JA005089, 2003.

Fedorov, A., Dubinin, E., Song, P., Budnik, E., Larson, P., and Sauvaud, J.-A.: Characteristics of the exterior cusp for steady southward IMF: Interball observations, J. Geophys. Res., 105, No A7, 15 945-15 957, 2000.

Frey, H. U., Phan, T. D., Fuselier, S. A., and Mende, S. B.: Continuous magnetic reconnection at Earth's magnetopaue, Nature, 426, No. 6966, 533-537, 2003.

Fuselier, S. A., Trattner, K. J., and Petrinec, S. M.: Cusp observations of high and low-laltitude reconnection for northward IMF, J. Geophys. Res., 105, No. A1, 253-266, 2000a.

Fuselier, S. A., Petrinec, S. M., and Trattner, K. J.: Stability of the high-Latitude reconnection site for steady northward IMF, Geophys. Res. Lett., 27, 473-476, 2000 b.

Gosling, J. T., Thomsen, M. F., Bame, S. J., Elphic, R. C., and Russel, C. T.: Observations of reconnection of interplanetary and lobe magnetic field lines at high-latitude magnetopause, J. Geophys. Res., 96, No. A8, 14 097-14 106, 1991.

Haerendel, G.: Microscopic plasma processes related to reconnection, J. Atmos. Terr. Phys., 40, No. 3, 343-353, 1978.

Haerendel, G., Paschmann, G., Sckopke, N., Rosenbauer, H., and Hedgecock, P. C.: The Frontside Boundary Layer of the Magnetosphere and the Problem of Reconnection, J. Geophys. Res., 83, No. A7, 3195-3216, 1978. 
Hansen, A. M., Bahnsen, A., and D'Angelo, N.: The CuspMagnetosheath Interface, J. Geophys. Res., 81, No. 4, 556-561, 1976.

Harvey, C. C.: Spatial gradients and the volumetric tensor, Analysis methods for Multi-spacecraft data, Int. Space Sci. Inst. Scientific Report Book, SR-001, 307-322, 1998.

Johnstone, A. D., Alsop, C., Burge, S., Carter, P. J., Coates, A. J., Coker, A. J., Fazakerley, A. N., Grande, M., Gowen, R. A., Gurgiolo, C., Hancock, B. K., Narheim, B., Preece, A., Sheather, P. H., Winningham, J. D., and Woodliffe, R. D.: PEACE: A plasma electron and current experiment, Space Science Reviews, 79, No. 1-2, 351-398, 1997.

Kessel, R. L., Chen, S.-H., Green, J. L., Fung, S. F., Boardsen, S. A., Tan, L. C., Eastman, T. E., Craven, J. D., and Frank, L. A.: Evidence of high-latitude reconnection during northward IMF: Hawkeye observations, Geophys. Res. Lett., 23, No. 5, 583-586, 1996.

Lavraud, B., Dunlop, M. W., Phan, T. D., Rème, H., Bosqued, J. M., Dandouras, I., Sauvaud, J.-A., Lundin, R., Taylor, M. G. G. T., Cargill, P. J., Mazelle, C., Escoubet, C. P., Carlson, C. W., McFadden, J. P., Parks, G. K., Moebius, E., Kistler, L. M., Bavassano-Cattaneo, M.-B., Korth, A., Klecker, B., and Balogh, A.: Cluster observations of the exterior cusp and its surrounding boundaries under northward IMF, Geophys. Res. Lett., 29, No. 20, 56-60, doi:10.1029/2002GL015464, 2002.

Lavraud, B., Fedorov, A., Budnik, E., Grigoriev, A., Cargill, P. J., Dunlop, M. W., Rème, H., Dandouras, I., and Balogh, A.: Cluster survey of the high-altitude cusp properties: A three-year statistical study, Ann. Geophys.,in press, 2004.

Nykyri, K., Cargill, P. J., Lucek, E. A., Horbury, T. S., Balogh, A., Lavraud, B., Dandouras, I., and Rème, H.: Ion cyclotron waves in the high altitude cusp: CLUSTER observations at varying spacecraft separations, Geophys., Res. Lett., 24, 2263-2266, doi: 10.1029/2003GL018594, 2003.

Onsager, T. G., Scudder, J. D., Lockwood, M., and Russell, C. T.: Reconnection at the high latitude magnetopause during northward interplanetary magnetic field conditions, J. Geophys. Res., 106, No. A11, 25 467-25 488, 2001.

Paschmann, G., Haerendel, G., Sckopke, N., Rosenbauer, H., and Hedgecock, P. C.: Plasma and Magnetic Field Characteristics of the Distant Polar Cusp Near Local Noon: The Entry Layer, J. Geophys. Res., 81, No. 16, 2883-2899, 1976.

Paschmann, G., Baumjohann, W., Sckopke, N., Phan, T. D., and Lühr, H.: Structure of the dayside magnetopause for low magnetic shear, J. Geophys. Res., 98, No. A8, 13 409-13 422, 1993.

Petrinec, S. M., Trattner, K. J., and Fuselier, S. A: Steady reconnection during intervals of northward IMF - implications for magnetosheath properties, J. Geophys. Res., 108, No. A12, 1458, doi:10.1029/2003JA009979, 2003.

Phan, T. D., Paschmann, G., Baumjohann, W., Sckopke, N., and Lühr, H.: The magnetosheath region adjacent to the dayside magnetopause: AMPTE/IRM observations, J. Geophys. Res., 99, No. A1, 121-141, 1994.

Phan, T. D., Frey, H. U., Frey, S., Peticolas, L., Fuselier, S. A., Carlson, C., Rème, H., Bosqued, J.-M., Balogh, A., Dunlop, M. W., et al.: Simultaneous Cluster and IMAGE observations of cusp reconnection and auroral proton spot for northward IMF, Geophys. Res. Lett., 30, No. 10, 16-19, doi:10.1029/2003GL016885, 2003.

Rème, H., Aoustin, C., Bosqued, J. M., Dandouras, I., Lavraud, B., Sauvaud, J.-A., Barthe, A., Bouyssou, J., Camus, Th., CœurJoly, O., Cros, A., Cuvilo, J., Ducay, F., Garbarowitz, Y., Médale,
L. J., Penou, E., Perrier, H., Romefort, D., Rouzaud, J., Vallat, C., Alcaydé, D., Jacquey, C.,Mazelle, C., d'Uston, C., et al.: First multispacecraft ion measurements in and near the earth's magnetosphere with the identical CLUSTER Ion Spectrometry (CIS) Experiment, Ann. Geophys., 19, No. 10-12, 1303-1354, 2001.

Rosenbauer, H., Gruenwaldt, H., Montgomery, M. D., Paschmann, G., and Skopke, N.: HEOS-2 plasma observations in the distant polar magnetosphere: the plasma mantle, J. Geophys. Res., 80, No. 19, 2723-2737, 1975.

Russell, C. T., Le, G. and Petrinec, S. M.: Cusp observations of high and low latitude reconnection under northward IMF: and alternate view, J. Geophys. Res., 105, No. A3, 5489-5495, 2000.

Russell, C. T.: POLAR eyes the cusp, Proc. of the Cluster II Workshop: Multiscale/Multipoint Plasma Measurements, ESA SP449, 47-55, 2000.

Savin, S. P., Romanov, S. A., Fedorov, O., Zelenyi, L., Klimov, S. L., Yermolaev, Y. L., Budnik, E. Y., Nikolaeva, N. S., Russell, C. T. et al.: The cusp / magnetosheath interface on May 29, 1996 Interball 1 and Polar Observations, Geophys. Res. Lett., 25, No. 15, 2963-2966, 1998.

Savin, S., Zelenyi, L., Maynard, N., Sandahl, I., Kawano, H., Russell, C. T., Romanov, S., Amata, E., Avanov, L., Blecki, J., et al.: Multi-spacecraft Tracing of Turbulent Boundary Layer, Adv. Space Res., 30, No. 12, 2821-2830, 2002.

Savin, S., Zelenyi, L., Romanov, S., Sandahl, I., Pickett, J., Amata, E., Avanov, L., Blecki, J., Budnik, E., Buechner, J., Cattell, C., Consolini, G., Fedder, J., Fuselier, S., et al.: Magnetosheath Cusp Interface, Ann. Geophys., 22, 183-212, 2004.

Scarf, F. L., Fredericks, R. W., Neugebauer, M., and Russell, C. T.: Plasma waves in the dayside polar cusp 2 - Magnetopause and Polar magnetosheath, J. Geophys. Res., 79, No. 4, 511-520, 1974.

Sibeck, D. G., Paschmann, G., Treumann, R. A., Fuselier, S. A., Lennartsson, W., Lockwood, M., Lundin, R., Ogilvie, K. W., Onsager, T. G., Phan, T. D., et al.: Chapter 5-Plasma Transfer Processes at the Magnetopause, Space Sci. Rev., 88, No. 1-2, 207-283, 1999.

Smith, M. F. and Lockwood, M.: Earth's magnetospheric cusps, Reviews of Geophysics, 34, No. 2, 233-260, 1996.

Sonnerup, B. U. O. and Cahill, L. J.: Magnetopause structure and attitude from Explorer 12 observations, J. Geophys. Res., 72, No. $1,171,1967$.

Sonnerup, B. U. O., Papamastorakis, I.,Paschmann, G. and Lühr, H.: Magnetopause properties from AMPTE/IRM observations of the convection electric field method development, J. Geophys. Res., 92, No. A11, 12 137-12159, 1987.

Szita, S., Fazakerley, A. N., Carter, P. J., James, A. M., Travinicek, P., Watson, G., Andre, M., Eriksson, A., and Torkar, K., Ann. Geophys., 19, No. 10-12, 1721-1730, 2001.

Tsyganenko, N. A.: A magnetospheric magnetic field model with a warped tail current sheet, Planet. Space Sci., 37, No. 1, 5-20, 1989.

Tsyganenko, N. A., and Russell, C. T.: Magnetic signatures of the distant polar cusps: Observations from Polar and quantitative modeling, J. Geophys. Res., 104, 24 939-24955, 1999.

Vasyliunas, V. M.: Multi-branch model of the open magnetopause, Geophys. Res. Lett., 22, No. 9, 1245-1247, 1995.

Vontrat-Reberac, A., Bosqued, J. M., Taylor, M. G., Lavraud, B., Fontaine, D., Dunlop, M. W., Laakso, H., Cornilleau-Werhlin, N., Canu, P., and Fazarkerley, A.: Cluster observations of the high-altitude cusp for northward interplanetary magnetic field: a case study, J. Geophys. Res., Vol. 108, No. A9, 1346, 
doi:10.1029/2002JA009717, 2003.

Walters, G. K.: On the existence of a second standing shock wave attached to the magnetosphere, J. Geophys. Res., 71, No. 5, 1341, 1966.

Yamauchi, M. and Lundin, R.: The wave-assisted cusp model: Comparison to low-altitude observations, Phys. Chem. Earth, 22, 729-734, 1997.
Zwan, B. J. and Wolf, R. A.: Depletion of solar wind plasma near a planetary boundary, J. Geophys. Res., 81, No. 10, 1636-1648, 1976. 